\title{
COMMENTARY
}

\section{Embarking as Captain of the Ship for the Curriculum Committee}

Kristin K. Janke, PhD, ${ }^{a}$ Krisy-Ann Thornby, PharmD, ${ }^{b}$ Kristy Brittain, PharmD, ${ }^{\mathrm{c}}$ Mariann Churchwell, PharmD, ${ }^{\mathrm{d}}$ Kathleen Hill-Besinque, PharmD, MSEd, ${ }^{\text {e }}$ Sharon K. Park, PharmD, Med, ${ }^{\mathrm{f}}$ Helen Smith, PhD ${ }^{\mathrm{g}}$

${ }^{a}$ University of Minnesota, College of Pharmacy, Minneapolis, Minnesota

${ }^{\mathrm{b}}$ Palm Beach Atlantic University, Gregory School of Pharmacy, West Palm Beach, Florida

${ }^{\mathrm{c}}$ Medical University of South Carolina, College of Pharmacy, Charleston, South Carolina

${ }^{\mathrm{d}}$ University of Toledo, College of Pharmacy and Pharmaceutical Sciences, Toledo, Ohio

${ }^{\mathrm{e}}$ Chapman University, School of Pharmacy, Orange, California

${ }^{\mathrm{f}}$ Notre Dame of Maryland University, School of Pharmacy, Baltimore, Maryland

${ }^{\mathrm{g}}$ University of the Incarnate Word, Feik School of Pharmacy, San Antonio, Texas

Corresponding Author: Krisy-Ann Thornby, Palm Beach Atlantic University, Gregory School of Pharmacy, 901 S. Flagler Dr., West Palm Beach, FL 33416-4708. Tel: 561-803-2724. Email: Krisy_Thornby@pba.edu

Submitted April 15, 2021; accepted July 19, 2021; ePublished August 2021

This commentary examines the curriculum chair's responsibilities and discusses considerations when assuming this role, using a captain of the ship metaphor. From knowing the crew to managing a diverse set of responsibilities, the path to becoming an effective chair is challenging and each captain's stripe must be earned. Advice is provided to assist with understanding the curriculum and governance processes, as well as the chair's various roles and professional development. The need for both leadership and management is also emphasized.

Keywords: curriculum, faculty, accreditation, management, leadership

\section{INTRODUCTION}

There was the signature knock on my office door one afternoon last week - the warning when our department chair needs a favor. This time she needed a new curriculum committee chair. I had served on smaller committees for several years, contributing, helping overcome some challenges, and meeting deadlines. But this was different. Faculty have very strong opinions of what should change, and for many, their piece of the curriculum is personal. Plus, there are so many charges for the year! Why did I say yes? Curriculum chair? How will I do a good job??

Chairing the curriculum committee for a professional program is an overwhelming, yet noble role, central to the school's academic success. Like the captain of a ship, the curriculum committee chair (hereafter referred to as "chair") is a position of responsibility both for the ship (the curriculum), as well as its cargo (resources) and crew/passengers (faculty and students). The captain oversees navigation to the destination, ensures compliance with laws (standards) and maintains documentation. They are responsible both when there is smooth sailing and turbulent waters. The success of any particular journey (educational initiative) is tightly tied to the captain's abilities, as well as their ability to effectively engage the crew.

The captain metaphor may resonate in many ways. For instance, it may be important for the chair to spend time with a telescope to see into the distance. Likewise, the chair must avoid any sort of mutiny! However, the metaphor is not perfect. Making curriculum-related decisions, implementing them, and monitoring the results involves an intricate process of shared governance, unlike the clear authority and accountability that may be present on a ship. An effective chair knows the curriculum, understands school governance, executes their various roles as chair, engages in self-development to enhance their effectiveness, and monitors the balance between management and leadership. To aid the new chair, this commentary provides an overview of these issues. With its interest in supporting faculty as they assume new roles, the American Association of Colleges of Pharmacy (AACP) Council of Faculties charged the Curriculum Learning Community to develop this commentary.

\section{Know the Curriculum}

Just as the captain needs an understanding of the ship's structure, its capabilities, and its capacities, the curriculum chair needs an understanding of the curriculum. When it comes to curriculum, complexities abound, perhaps because "curriculum is the most holistic, inclusive and comprehensive entity and notion in education." ${ }^{1}$ Faculty generally know which courses are taught in which semesters and how courses within a series are designed to help students progress 
toward graduation. However, curricular structure and sequencing are just the beginning of understanding the curriculum. Table 1 provides an overview of curriculum design-related questions that can help the chair develop an understanding of the curriculum. In addition, the chair must also have an awareness of the differences between the intended curriculum, the implemented curriculum, and the learned curriculum. ${ }^{2}$ The intended curriculum is the envisioned, planned curriculum that is represented in official documents (eg, courses listed in the school's catalog). However, when instruction is delivered (ie, implemented curriculum), the planned curriculum may be altered in response to unanticipated problems (eg, snow day), resource changes, student performance, etc. The achieved or learned curriculum reflects what is received by learners (eg, the experience, outcomes or competencies) that can be assessed, evaluated, and/or demonstrated. For a host of reasons, the implemented curriculum may not achieve the desired learning outcomes, requiring action. The chair must also be aware of the presence and impact of the hidden curriculum, which is operating through the organization's structure and culture. This hidden curriculum may include "understandings," messages about what is and is not valued and taken-for-granted aspects of what happens within the program. The implicit values and norms of the hidden curriculum can be reinforced or undermined by policy development, evaluation, resource allocation, and institutional nomenclature. ${ }^{3}$ Therefore, the chair should ask "What are the fundamental values and messages being created and transmitted as we engage in these activities?" Curricula are complex. In addition to the structure, sequencing and outcomes, the chair must also be aware of the intended, delivered, learned and hidden curricula.

\section{Understand School Governance}

Accomplishing the charges (and mission) of the committee will require an understanding of the organization's structure, policies and procedures, as well as working with various stakeholders (eg, college and university administrators, faculty, preceptors, students). Casiro and Regehr state that "the means by which decisions are made, implemented and monitored constitute the governance of a program."4 They argue that good governance includes three dimensions: authority, decision-making, and accountability. As chair, what will be your authority, decision-making, and accountability? The route to good governance may be less than clear. Table 1 provides questions to ponder and actions to take to support the chair's work in governance. The chair needs to understand the mechanisms for communication and dialogue, be sensitive to conflicting interests and minority viewpoints, and clarify and shape processes for decisionmaking and accountability. In order to enact recommendations and change, the committee also needs effective sponsorship from one or more administrators. The chair should work closely with these sponsors to ensure clarity on priorities for the committee and timely, bi-directional communication.

\section{Recognize Multiple Roles of the Chair}

When observing a chair, it may appear as if their role is primarily in agenda coordination (eg, meeting management). However, this is far from the case. Stark and colleagues outline other roles, which are summarized in Table 2 , with possible tasks or actions. ${ }^{5}$ In order to keep the committee moving forward productively, the chair needs to recognize when a particular role is needed. For example, in the same manner in which a captain can sense stormy weather and charts a route to clear passage, the chair-as-sensor is keenly aware of curricular issues within the school and externally, bringing these to the group's attention. Another common role is the advocate. Just as the captain requests assistance from persons ashore, or nearby ships (eg assessment, student affairs), the chair-as-advocate will need to procure resources or clarify priorities with others in the chain of command. The chair may find themselves shifting roles even in the midst of a particular meeting or conversation.

\section{Commit to Professional Development}

Professional development is necessary for a captain to effectively lead the curriculum and gain the trust of the crew, passengers, and neighboring ships. As mentioned in Table 2, faculty will often recognize the chair as the curriculum liaison, which requires an understanding of factors affecting pharmacy curriculum and health sciences education. Keeping current on educational trends can be difficult and a supportive network of colleagues is essential. Consider becoming a member of the AACP Curriculum Special Interest Group and/or attending the AACP Annual Meeting. In addition, plan to actively scan the horizon for pharmacy education articles specific to active committee charges (eg, course review processes). To begin the learning process, Dorval et al. have described useful resources for curriculum committee members as it relates to curricular terminology, syllabus review, teaching methods, course review, student workload, and interprofessional education (IPE) ${ }^{6}$

When planning professional development, consider the major work that is needed during the appointment term. There might be a new design or development project (eg, updating quality assurance measures), a college-wide implementation initiative (eg, mapping, new technology), a major evaluative cycle (eg, course review, accreditation selfstudy) or a challenge (eg, addressing student workload). Perhaps there is knowledge to be gained to aid immediate 
curriculum design and decision-making, such as curriculum development process, information on spiraling, use of portfolios or approaches to supporting professional identity formation. ${ }^{7-11}$ The implementation of the curriculum, and feedback from assessment and evaluation, may also be generating learning-related needs, such as strategies for managing cognitive load or encouraging deliberative practice. ${ }^{12}$ Depending on the major work being planned, it might be helpful to learn about program evaluation (eg, use of logic models) or particular technologies being used to support the curriculum. ${ }^{13}$ It is not necessary to learn everything, but strategic learning priorities should be identified.

\section{Use Both Management and Leadership}

As presented by McKimm and Swanwick, educational leaders carry a "double burden" to both lead and manage the many aspects of their work. ${ }^{14}$ This is also true of curriculum committee chairs. Leadership is generally about change and movement, and management is about order and consistency. ${ }^{14}$ Kotter describes leadership and management as "two distinctive and complementary systems of action," each with distinct functions and activities. ${ }^{15}$

Management typically involves planning, budgeting, organizing, staffing, and maintaining order (eg, monitoring and reporting).${ }^{15}$ For example, the chair must monitor the academic calendar, ensuring that decisions (eg, whether to approve a new course) and tasks (eg, the course review process) are completed on time. Leadership is about guiding change..$^{15}$ Leadership involves setting direction as well as motivating, inspiring and aligning people. ${ }^{15}$ For example, the chair may need to build commitment among faculty and students for the launch of a new IPE initiative and work to help them see the benefits. Major curricular efforts may require buy-in from many individuals and groups outside of the committee. The chair may also encounter committee initiatives that are reliant on other staff or committees. All of the situations will require strong relationships with others.

Effective chairs, like good captains, need to utilize both management and leadership skills. In particular, the chair needs to oscillate between problem-solving (management) and problem-defining (leadership). ${ }^{14}$ For example, the onset of the COVID-19 pandemic involved quick pivoting to online learning that required nimble problem-solving often on a dayby-day basis. However, leadership is needed post-pandemic to help chart a new course, potentially exploring hybrid models that blend online and live instruction. In these cases, the chair may need to provide information, raise questions, and suggest options to help the members address the new reality.

\section{Utilize the Team and Set Expectations}

With the many roles of the chair, rapidly changing environments, and a dynamic set of charges, the responsibilities of the chair can easily become overwhelming. To ensure productivity, managing time and maintaining order are crucial aspects of committee meetings. Like the captain who looks to the officers and crew for support, the chair must look to the members and staff. For example, there may be the need for a formal first officer (co-chair or vice chair) to share the responsibilities and enable strong continuity over time (ie, preparing them for chair responsibilities). Is there a shipmate designated for minutes or, in the age of real-time document sharing, are they crowdsourced and reviewed by the committee as a whole? The answer may depend on organizational culture, history, and the willingness to experiment with new processes. The chair needs to have a sense of these school-specific, contextual variables when attempting to assemble the necessary support.

In addition, while the captain needs a working knowledge of the galley, there is no need for the captain to make the meals. The chair needs to be aware of the expertise, interests, and commitment levels of the members and should work to align members with initiatives that draw on their talents. Subcommittees may need to be created for efficiency. Ideally, the membership is sufficiently diverse, connected, and respected to allow information and input to be collected that enables the group to do its work. The credibility and influence of members can have a powerful positive impact in navigating highly charged or political issues. The committee should be sufficient in size to accommodate changes (eg, parental leaves) or temporary members may need to be appointed. Expertise, such as instructional designers or assessment personnel, needs to be available, if not specifically appointed to the committee. The captain must consider the journey ahead when assessing the expertise required in the crew. When possible, the chair should advocate for strong membership, suggesting appointments to help diversify the group and provide coverage for the various skill sets needed.

The chair will need to set expectations with the group. For example, how will respectful and inclusive conversations occur? How will the group engage in meaningful deliberation? How does the group work through conflict? When decisions are made, how are they communicated and supported? New members may require an orientation process (eg, trends in pharmacy education, curriculum-related procedures) to ensure they are prepared for the conversations and tasks of the group.

\section{CONCLUSION}


While sipping coffee and preparing for my final meeting as 'curriculum chair,' I realize how quickly time has passed in my term. I scan the agenda where we will recap the progress we've made. This journey required me to learn more about the intended, delivered and learned curriculum, as well as the hidden curriculum. At times, I found myself jumping back and forth between being a coordinator, initiator, facilitator, and advocate, among other roles. Throughout my term, I was continuously mindful of the need for accountability and cautiously navigated issues of authority and processes for decision-making. Governance was always on my mind. Along the way, our success was bolstered by the intentional involvement of stakeholders and productive engagement of sponsors. Both my management and leadership skills were tested as unanticipated charges were added and challenges arose from both internal and external to the committee. There were detours and temporary setbacks, but each created the opportunity for me to learn, as well as adding to our collective institutional wisdom. While I was the one who captained the ship on this voyage, our safe arrival was the result of a collective effort. With our short-term charges and the committee's long-range initiatives as our compass, we arrived at this port, moving us in the right direction for the good of our program and our students. Now we can look to make further progress as we seek our next destination and welcome the new chair.

\section{REFERENCES}

1. Genn JM. AMEE medical education guide no. 23 (part 1): Curriculum, environment, climate, quality and change in medical education - A unifying perspective. Med Teach. 2001;23(4):337-344. doi:10.1080/01421590120063330

2. International Bureau of Education. Different meanings of "curriculum." http://www.ibe.unesco.org/en/geqaf/annexes/technical-notes/different-meanings\%E2\%80\%9Ccurriculum\%E2\%80\%9D Accessed July 12, 2021.

3. Hafferty FW. Beyond curriculum reform. Acad Med. 1998;73(4):403-407.

4. Casiro O, Regehr G. Enacting pedagogy in curricula: on the vital role of governance in medical education. Acad Med. 2018;93(2):179-184. doi:10.1097/ACM.0000000000001774

5. Stark JS, Briggs CL, Rowland-Poplawski J. Curriculum leadership roles of chairpersons in continuous planning departments. Res High Educ. 2002; 43(3): 329-356. doi.org/10.1023/A:1014841118080

6. Dorval E, Thornby KA, Ottman A, Hubbard M. Useful resources for members serving on a curriculum committee in schools and colleges of pharmacy. Curr Pharm Teach Learn. 2017;9(1):145-154. doi:10.1016/j.cptl.2016.08.050

7. Wehrli G. The nuts and bolts of curriculum and assessment. J Clin Apher. 2011;26(1):29-46. doi:10.1002/jca.20265

8. Schneiderhan J, Guetterman TC, Dobson ML. Curriculum development: a how to primer. Fam Med Community Health. 2019;7(2):e000046. doi:10.1136/fmch-2018-000046

9. Grant J. Principles of Curriculum Design. In: Understanding Medical Education. John Wiley \& Sons, Ltd; 2018:71-88. doi:10.1002/9781119373780.ch5

10. Driessen E, van Tartwijk J. Portfolios in Personal and Professional Development. In: Understanding Medical Education. John Wiley \& Sons, Ltd; 2018:255-262. doi:10.1002/9781119373780.ch18

11. Cruess SR, Cruess RL. The Development of Professional Identity. In: Understanding Medical Education. John Wiley \& Sons, Ltd; 2018:239-254. doi:10.1002/9781119373780.ch17

12. de Bruin ABH, Sibbald M, Monteiro S. The Science of Learning. In: Understanding Medical Education. Vol 311. John Wiley \& Sons, Ltd; 2018:23-36. doi:10.1002/9781119373780.ch3

13. Lovato C, Peterson L. Programme Evaluation. In: Understanding Medical Education. John Wiley \& Sons, Ltd; 2018:443-455. doi:10.1002/9781119373780.ch30

14. McKimm J, Swanwick T. Educational Leadership and Management. In: Swanwick T, Forrest K, O’Brien BC, eds. Understanding Medical Education: Evidence, Theory and Practice. Wiley Blackwell; 2019:549-568.

15. Kotter JP. What leaders really do. Harv Bus Rev. 1990;68(3):103-111.

16. Accreditation Council for Pharmacy Education. Accreditation Standards and Key Elements for the Professional Program in Pharmacy Leading to the Doctor of Pharmacy Degree. Published 2015. https://www.acpeaccredit.org/pdf/Standards2016FINAL.pdf Accessed July 12, 2021.

17. NAPLEX: North American Pharmacist Licensure Examination, National Association of Boards of Pharmacy. NAPLEX Competency Statements. https://nabp.pharmacy/programs/examinations/naplex/competencystatements-2021/ Accessed July 12, 2021.

18. Flannery AH, Soric MM, Benavides S, et al. 2019 Update to the American College of Clinical Pharmacy Pharmacotherapy Didactic Curriculum Toolkit. J Am Coll Clin Pharm. 2020; 3:455- 464. https://doi.org/10.1002/jac5.1178 
19. ASHP long-range vision for the pharmacy workforce in hospitals and health systems. Am J Health Syst Pharm. 2020;77(5):386-400. doi:10.1093/ajhp/zxz312

20. Pittenger AL, Chapman SA, Frail CK, Moon JY, Undeberg MR, Orzoff JH. Entrustable Professional Activities for Pharmacy Practice. Am J Pharm Educ. 2016;80(4):57. doi:10.5688/ajpe80457

Table 1. Suggested Questions to Develop Understanding of the Curriculum

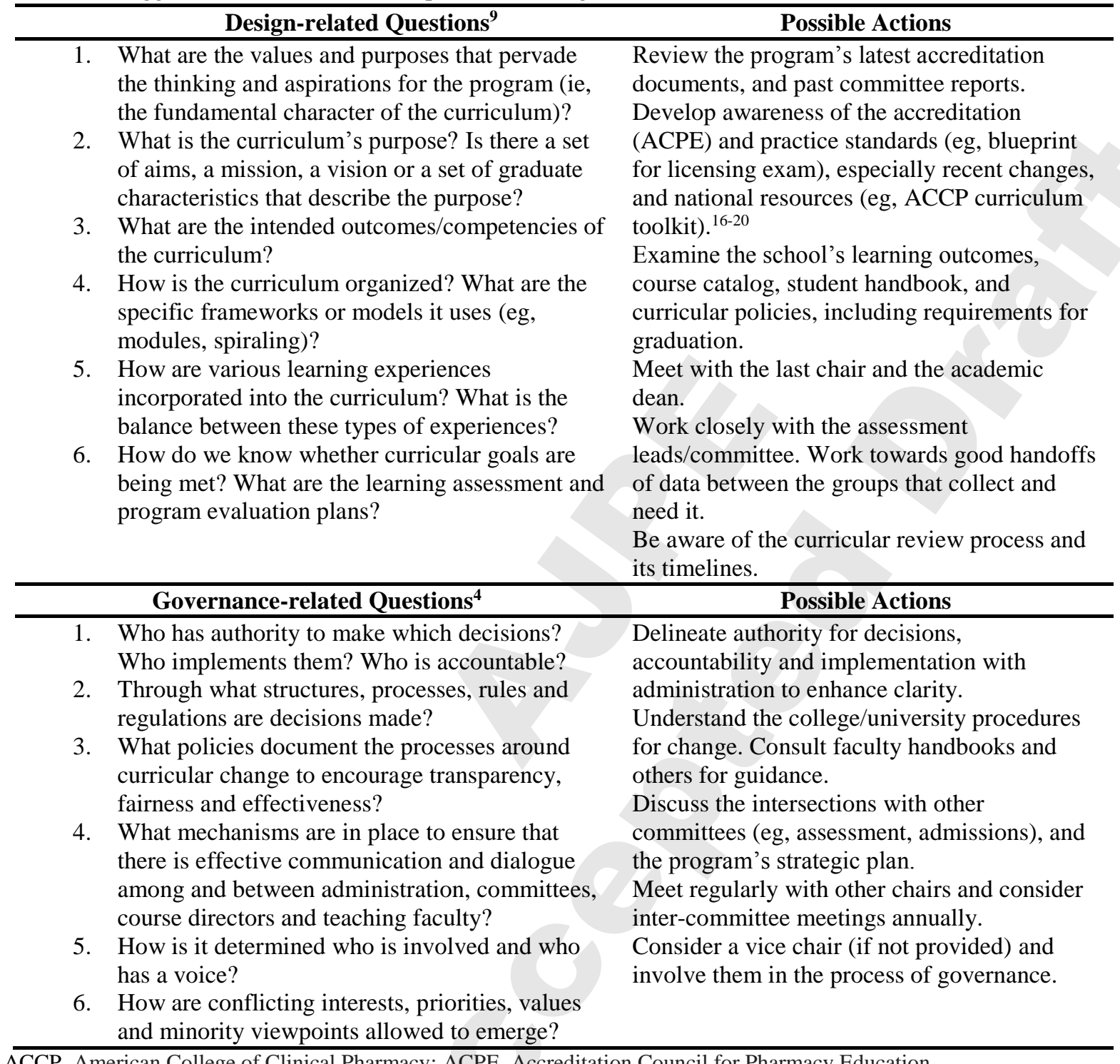

ACCP, American College of Clinical Pharmacy; ACPE, Accreditation Council for Pharmacy Education 
Table 2. Seven Common Roles of Curriculum Chairs and Related Advice

\begin{tabular}{|c|c|c|}
\hline Role $^{\mathbf{a}}$ & Characteristics & Possible Curriculum Chair Tasks or Actions \\
\hline Agenda Setter & Gives charges to the committee & $\begin{array}{l}\text { Collects and prioritizes requests of the } \\
\text { committee. Assigns due dates to meet short- } \\
\text { and long-term targets. }\end{array}$ \\
\hline Coordinator & $\begin{array}{l}\text { Provides structure, task orientation, and } \\
\text { paperwork support } \\
\text { Functions as a 'manager,' and 'juggler' }\end{array}$ & $\begin{array}{l}\text { Oversees a system for relevant curricular } \\
\text { information (eg, program outcomes, curriculum } \\
\text { mapping documents). } \\
\text { Creates or updates tracking systems regularly } \\
\text { when curriculum changes occur. }\end{array}$ \\
\hline Sensor & $\begin{array}{l}\text { Provides direction to the committee } \\
\text { A 'vision setter' }\end{array}$ & $\begin{array}{l}\text { Develops an attuned awareness of curricular } \\
\text { problems and opportunities internally (eg, } \\
\text { within the faculty or school) and externally (eg, } \\
\text { regional, national). Introduces timely curricular } \\
\text { topics to key stakeholders. }\end{array}$ \\
\hline Initiator & Introduces ideas, proposals, and drafts & $\begin{array}{l}\text { Researches best practices from the literature } \\
\text { and/or seeks examples from external contacts. } \\
\text { Interacts with AACP's curriculum special } \\
\text { interest group. }\end{array}$ \\
\hline Facilitator & $\begin{array}{l}\text { A 'process leader,' 'integrator,' 'idea } \\
\text { prompter' }\end{array}$ & $\begin{array}{l}\text { Organizes strategic planning sessions for } \\
\text { faculty and stakeholders to initiate effective } \\
\text { curricular conversations and encourage a sense } \\
\text { of shared faculty ownership and consensus. } \\
\text { Observes committee members' strengths and } \\
\text { interests to appoint appropriate subcommittees. } \\
\text { Identifies the key curriculum stakeholders or } \\
\text { champions. }\end{array}$ \\
\hline Advocate & $\begin{array}{l}\text { Serves as an intermediary between } \\
\text { administration, faculty and committee } \\
\text { members } \\
\text { A 'resource procurer,' 'priority setter,' } \\
\text { 'communicator' }\end{array}$ & $\begin{array}{l}\text { Fosters collaborative relationships with } \\
\text { administrators, directors and other chairs, } \\
\text { including IPE leaders, co-curriculum leaders, } \\
\text { information technology staff. } \\
\text { Initiates conversations with administration to }\end{array}$ \\
\hline Standard Setter & $\begin{array}{l}\text { May be referred to as a curricular 'role } \\
\text { model,' 'time protector', 'quality } \\
\text { monitor' }\end{array}$ & $\begin{array}{l}\text { Serves as a model example for peer faculty } \\
\text { members to have a 'go to' for best practices. } \\
\text { Ensures that quality assurance measures are } \\
\text { being conducted amid routine tasks. }\end{array}$ \\
\hline
\end{tabular}

${ }^{a}$ Roles and characteristics modified from Stark and colleagues ${ }^{5}$ 